\title{
Neurosurgical education in Europe
}

\author{
Jannick Brennum ${ }^{1}$ (D) $\cdot$ Johannes van Loon $^{2}$
}

Received: 29 October 2015 / Accepted: 2 November 2015 / Published online: 12 November 2015

(C) Springer-Verlag Wien 2015

Two articles in this issue of Acta Neurochirurgica by Steinen et al. investigate current neurosurgical education in Europe, based on the largest and most comprehensive survey amongst trainees so far $[1,2]$. The main conclusions the authors draw from the survey are: (1) The theoretical and practical aspects of neurosurgical training are highly variable throughout European countries. (2) Less than $40 \%$ of the $>500$ responders participate in training programmes that adhere to the European Working Time directive with a maximum weekly working time of $48 \mathrm{~h}$ [2]. The authors describe the European Working Time directive as a bureaucratic constraint hindering highquality postgraduate training.

It at first certainly does seem impossible to educate neurosurgeons to an even better standard than previously, with reduced training time and at the same time exponentially increasing complexity created by our scientific endeavours. We need to take a closer look at two factors that are determinant of successful neurosurgical training:

- What are the goals of the neurosurgical training programme?

- What are the organisational goals for the individual unit running the training programme?

Jannick Brennum

Jannick.brennum@regionh.dk

1 Copenhagen Neurosurgery, Neuroscience Centre, Rigshospitalet, University of Copenhagen, Blegdamsvej 9, 2100 Copenhagen $\varnothing$, Denmark

2 Department of Neurosurgery, University Hospitals Leuven, Leuven, Belgium

\section{What are the goals of the neurosurgical training programme?}

To answer this question we need to consider the organisational future of neurosurgery. The time of the neurosurgical "jack of all trades" is past. The present and future must be based on increased subspecialisation and teamwork. Neurosurgery has long surpassed a degree of complexity where a single neurosurgeon can master the theoretical knowledge and practical skills of all subspecialties at a sufficiently high level. Accordingly, most neurosurgical units have already implemented subspecialisation, where the individual neurosurgeons work together as a team to deliver high-quality services. Furthermore, collaboration between units is called for when dealing with rare conditions. In order to support this subspecialisation a neurosurgical training programme needs to deliver basic neurosurgical training that allows the further development into subspecialties. Such subspecialisation may begin in the final year of the training programme or after its completion. There is a classical ethical dilemma inherent in training. The patients are best served when operated by a specialist rather than a trainee even if the trainee is supervised by the specialist. At the same time we need to train the specialist of the future. An obvious reasonable balance seems to be not to train trainees in procedures they are not likely to use when they have completed their training. An example is the clipping of aneurysms. In many countries learning to clip aneurysms was an integral part of the neurosurgical training programme in the past. It has since been removed from the curriculum as a result of the increasing subspecialisation and decreasing number of aneurysms being clipped. The neurosurgical UEMS (European Union of Medical Specialists) training charter [4], which forms the basis of the JRAAC (Joint Residency Advisory and Accreditation Committee) accreditation of training programmes, has evolved to reflect this development, as it will 
in the future. The next version has just been approved by the UEMS and will be released later this year [5].

\section{What are the organisational goals for the individual unit running the training programme?}

Although the main goal for a neurosurgical training programme should be to train excellent future neurosurgeons, in reality the trainees constitute a necessary workforce without whom it would not be possible to run most neurosurgical units with their current organisation. In some countries there is a set national number of neurosurgical training posts calculated to meet the future demand for neurosurgeons, e.g. in Denmark. In other countries there is no such consideration and it is left to the individual unit to decide on the number of trainees in their training programme. If the individual units are entering a surplus of trainees into their training programme because this is the only way they can secure a sufficient workforce of junior doctors, then neither the quality of the training nor future planning is the main objective. During JRAAC accreditations we have seen this problem addressed in different ways. Some of the more intelligent and productive ways have been the introduction of physician assistants, nurses or other paramedical professionals with added training, or transference of elements of the junior doctors' work to nurses, secretaries or other professions. Neurosurgical departments and national health boards need to focus the specialist training on adequate training for the organisation of the specialty and have to regulate the number of trainees according to future expectations. The current overproduction of neurosurgeons in some European countries is destined to result in a professional and social catastrophe for those who will not be able to secure a position when they have finished their neurosurgical training.

In agreement with a study 15 years ago [1], Steinen et al. demonstrate a marked variation in neurosurgical training within Europe. There are bound to be some regional variations in the way we practice neurosurgery in Europe. This is acceptable when it relates to the ways we as professionals interact with patients and organise hospitals and departments based on cultural differences. However, we should be steadfast in our goal to secure high-quality training in neurosurgery throughout Europe to reach the important goal of high-quality neurosurgical service in all of Europe. The EANS, UEMS and JRAAC strive in unison to support high-quality neurosurgical training in Europe. Some major initiatives are the EANS training courses, the success of which has stood the test of time. A more recent initiative is the EANS Academy, which is a substantial collection of high-grade lectures from the EANS courses, the EANS congresses and meetings as well as other educational materials. Other initiatives include EANS Observerships and HandsOn courses. The UEMS training charter has set a standard for neurosurgical training that all
European countries are advised to adhere to or even surpass when possible. The JRAAC uses the UEMS charter as the standard for accreditation. We have seen a slow rise in the number of units applying for JRAAC accreditation, and currently 16 neurosurgical units have full JRAAC accreditation in Europe, marking them as excellent training units [6]. Some countries have national accreditation programmes providing the same function as the JRAAC, which means that in total the number of training-accredited neurosurgical units is far higher than the 16 accredited by the JRAAC. As important as accreditation itself is the advice offered by the JRAAC to the individual units seeking accreditation to improve the training quality. The JRAAC shares the excellent ideas of some units with the others they visit.

In conclusion, we applaud Steinen et al. [2, 3] for producing the largest European training survey yet. We urge all European countries to regulate their neurosurgical training programmes to meet the demands of the future, in both a qualitative way that addresses the developing subspecialisation of neurosurgery and a quantitative way so we will not end up with a surplus of highly skilled but unemployed neurosurgeons in Europe. We urge all European countries to adopt national accreditation programmes built upon the example set by the JRAAC. We do not believe that the European Working Time directive is a bureaucratic hindrance to high-quality neurosurgical education in Europe. However, it has changed the rules of the game and the neurosurgical leaders have to incorporate these new rules intelligently in their game plan to secure the continued development of neurosurgery. The game has developed from a single player game to one that can only be played well by a fully integrated team.

\section{Compliance with ethical standard}

Funding No funding has been received for this study.

\section{References}

1. Brennum J (2000) European neurosurgical education - the next generation. Acta Neurochir (Wien) 142:1081-1087

2. Steinen MN, Netuka D, Demetriades AK, Ringel F, Gautschi OP, Gempt J, Kuhlen D, Schaller K (2015) Neurosurgical resident education in Europe - results of a multinational survey. Acta Neurochir (Wien)

3. Stienen MN, Netuka D, Demetriades A, Ringel F, Gempt J, Gautschi OP, Kuhlen DE, Schaller K (2015) Working Time of Neurosurgical Residents in Europe - results of a multinational survey. Acta Neurochir (Wien)

4. Reulen HJ, Lindsay KW (2007) UEMS charter on training of medical sepcialists in the EU- the neurosurgical training charter (as of February 2007). Acta Neurochir (Wien) 149:843-855

5. UEMS. European training requirements for the specialty of neurosurgery. European standards of postgraduate medical specialist training in neurosurgery

6. http://eans.org/pages/jraac 